\title{
Cultura Política e Consolidação Democrática em Cabo Verde: um Balanço de 24 anos da instauração da democracia
}

\section{Political Culture and Democratic Consolidation in Cape Verde: a balance of 24 years of democracy instauration}

Vlademiro Salvador Furtado ${ }^{1}$

\section{INTRODUÇÃO}

Este artigo procura examinar o processo de consolidação democrática em Cabo Verde do ponto de vista da cultura política, isto é, das atitudes e comportamentos dos cidadãos em relação à democracia. Para tanto, o texto parte da literatura sobre os processos de transição e consolidação democrática que, durante as décadas de 1980 e 1990, têm polarizado o debate político e acadêmico e se constituído em uma meta-agenda de produção de conhecimentos sobre a mudança dos sistemas políticos que varreu muitos Estados da Europa de Leste e do Sul, América Latina e África.

A par disso, o artigo apresenta uma revisão da literatura da cultura política e sua discussão no contexto da sociedade cabo-verdiana, tendo sempre como base as orientações e/ou disposições psicológicas, bem como o tipo de cultura política historicamente formatada e interiorizada pelos cidadãos cabo-verdianos. Neste sentido, o problema de pesquisa deste trabalho analisa o seguinte questionamento: que relação existe entre cultura política e consolidação democrática em Cabo Verde? Pode-se falar em consolidação após 24 anos de sua instauração e de ciclo ininterrupto de convivência democrática?

Dado esse questionamento, foi utilizada a metodologia qualitativa, baseada na análise documental de um lado e, de outro, na análise dos dados dos relatórios do Afrobarômetro sobre a qualidade da democracia e da governação em Cabo Verde. Assim sendo, foram selecionados,

\footnotetext{
${ }^{1}$ Doutorando em Ciência Política pela UFRGS, mestre em ciência política pelo ISCSP-Lisboa e graduado em filosofia pela UNICV, Cabo Verde. Analista Político da Rádio pública de Cabo Verde e colaborador permanente da Comissão Nacional de Eleições, Cabo Verde.
} 
neste trabalho, os relatórios das pesquisas tipo survey elaboradas pelo Afrobarômetro. Esses relatórios se estendem de 2002 a 2014 e correspondem à primeira e última ronda de pesquisa realizada no arquipélago pelo organismo.

\section{DEBATENDO O CONCEITO DE CONSOLIDAÇÃO DEMOCRÁTICA}

A erupção das "novas democracias" no cenário político mundial a partir da segunda metade do decênio de 1970 motivou grande interesse no campo da Ciência Política pelo estudo dos processos conducentes ao fortalecimento e consolidação democráticos nesses países. Esse crescente interesse está na base da grande polarização acadêmica e científica registrada a partir dos finais do século XX dando origem a um novo subcampo de estudos que se convencionou chamar por "Consolidalogia"” (O'DONNELL, 1996; SCHEDLER, 1998).

Assim, esse novo subcampo de estudos refletiu na produção teórica e empírica de um vasto número de estudos realizados a partir da terceira onda de democratização (HUNTINGTON, 1994) sobre os processos de transição e consolidação democráticas, dos quais se destacam, entre outros, os trabalhos de O’Donnell e Schmitter (1986), Mainwaring (1989); Schedler (1998) e Linz e Stepan (1996).

Todos esses estudos concentram sua argumentação nos desafios e possibilidades que as chamadas "novas democracias" enfrentam no processo de fortalecimento, sobrevivência e estabilidade democrática, evitando assim a erosão democrática ou o colapso do regime em alguma forma de autoritarismo.

Tais democracias, nas quais se incluem Cabo Verde, vêm sendo, desde a sua instauração ocorrida a partir dos meados de 1970, objeto de inúmeras críticas por parte dos defensores do liberalismo que depositam dúvidas quanto à possibilidade da sobrevivência democrática tendo em conta o horizonte temporal longo do autoritarismo vivenciado nesses países. Neste contexto, vale afirmar que Cabo Verde, enquanto nova democracia, e à semelhança do que aconteceu com as suas congêneres africanas, saiu de um regime de Partido Único, que sucedeu no poder

\footnotetext{
${ }^{2}$ Na literatura especializada sobre Ciência Política, este termo se refere a todo o manancial de trabalhos que enfoca os processos de consolidação democrática das novas democracias saídas a partir da terceira onda de democratização ocorrida no final da primeira metade da década de 70 do século XX.
} 
o colonialismo e que terá implantado, durante 15 anos consecutivos, processos e mecanismos governativos situados nos limites do autoritarismo.

Dado esse cenário ou espectro de autoritarismo historicamente vivenciado por essas "novas democracias", a Ciência Política Comparada tem tomado como referência a evidência empírica de consolidação democrática registrada nos países com democracias avançadas do eixo norte-ocidente para explicar os diversos, dinâmicos e complexos fatores internos que envolvem a consolidação democrática em países com transição democrática a partir da terceira vaga.

Nos países com democracia avançada, como são os casos dos países do eixo norteocidente, a literatura especializada tem enfatizado a importância da sociedade civil no processo de consolidação democrática, pois ela, além de se ter ao longo do tempo envolvido ativamente nos processos democráticos, tem manifestado atitudes e comportamentos congruentes com normas e valores fundamentais da democracia. Deste modo, a sociedade civil tem sido defendida por autores liberais na linha de Walzer (1990) como um elemento importante no processo de consolidação por contribuir no reforço das instituições democráticas.

A consolidação, mais do que mera permanência de instituições democráticas, envolve também outros fatores, como as atitudes, os comportamentos e a interiorização de normas e valores sem os quais as possibilidades de consolidação estariam comprometidas, pois a implantação da democracia não significa que todos os cidadãos a apoiem e se mostrem engajados em processos que visam o seu fortalecimento.

Assim sendo, cabe enfatizar a grande diversidade de sentidos para o conceito de consolidação no debate acadêmico levando a que diversos autores, dos quais se destaca O’Donnell (1996), o considerem como possuindo carácter polissêmico e amplo sentido, demarcando-se, assim, de certas abordagens minimalistas ${ }^{3}$ que o entendem como sinônimo de permanência ou longevidade democrática (O`Donnell,1996, pp. 37-38) .

\footnotetext{
${ }^{3}$ Tais abordagens referem-se à perspectiva de consolidação desenvolvida por Linz e Stepan no âmbito da qual dão a consolidação democrática como garantida quando "a democracia se tornar o único jogo da cidade". Para maiores informações, conferir: LINZ, Juan J. \& STEPAN, Alfred. Problems of Democratic Transition and Consolidation. Baltimore: Johns Hopkins University Press, 1996.
} 
Tendo em conta essa polissemia, O’Donnell (1996) sugere uma definição mais abrangente e que vai além da perspectiva clássica, na qual considera a dimensão institucional, bem como as normas e valores associados a ela, como elementos essenciais e caracterizadores da consolidação democrática. Em sua opinião, devem-se considerar duas dimensões importantes para a análise da consolidação. Uma dimensão institucional formal da poliarquia, cuja definição apresenta aquelas caraterísticas propostas por Dahl (1971), e outra dimensão institucional informal situada ao longo de práticas tradicionais da política, quais sejam: o particularismo ou o mais bem conhecido clientelismo, cuja presença se manifesta numa relação conflituosa com as regras formais.

Assim, esta noção diverge da perspectiva clássica sustentada por Linz segundo a qual uma poliarquia (democracia política) estaria consolidada quando ela perdura, isto é, quando os oficiais, eleitos através do voto secreto, justo, transparente e competitivo, tomam decisões vinculativas num cenário de ausência de poder de veto por parte de outras instituições sobre as autoridades eleitas (LINZ, 1990, p. 156).

Na mesma linha de raciocínio, Linz \& Stepan (1996) propõem como noção de uma democracia consolidada "um regime político no qual a democracia como um complexo sistema de instituições, regras, padrões de incentivos e desincentivos, se torna em uma frase: o único jogo na cidade" (LINZ; STEPAN, 1996, p. 15).

Em perspectiva oposta, O’Donnell (1996) considera que o problema que muitos pesquisadores apontam como sendo um empecilho à consolidação e, por conseguinte, à estabilidade democrática em muitas "novas democracias", não é a falta de institucionalização ou que seus processos de institucionalização falharam. Antes, pelo contrário, o problema estaria na forma como esses pesquisadores concebem a institucionalização e que os impede de ver que, além da dimensão institucional formal, perpassam também, nessas poliarquias, uma dimensão informal importante e que briga com aquilo que ele chama de "pacote institucional formal": o particularismo (O’DONNELL, 1996, p 35).

Na mesma linha de raciocínio, Schedler (2001, p. 67) afirma que a noção da consolidação democrática envolve tanto "um sentido positivo" de total aprofundamento da 
democracia liberal ou de complementaridade de uma semidemocracia quanto "um sentido negativo" de impedir a erosão ou o colapso da democracia liberal.

Nesta perspectiva, Diamond (1994) sugere que o fator mais urgente e importante no processo de consolidação democrática é, precisamente, a “institucionalização política”. Ele define a consolidação como o "processo no qual a democracia se torna amplamente e profundamente legitimada entre os cidadãos de forma a que ela não retroceda ou entre em erosão" (DIAMOND, 1994, p. 15).

Esta noção está embasada na ideia de que quanto maior o grau de institucionalização política maior será a possibilidade da emergência, manutenção e longevidade democrática. Posição semelhante aparece em Przerworski (1984) quando utiliza como argumento a ideia de que "uma democracia pode ser estabelecida somente se existirem instituições que tornem improváveis as consequências - decorrentes do processo político competitivo - altamente adversas aos interesses de qualquer agente específico, dada a distribuição de recursos econômicos, ideológicos, organizacionais, etc” (PRZERWORSKI, 1984, p. 39).

Portanto, essas noções apontam para aquilo que teóricos da transição e consolidação democráticas como O’Donnell (1996) classificam de visão teleológica, pois ligam diretamente a consolidação democrática com a chegada a total institucionalização ou a um movimento contínuo nessa direção, descurando outros elementos importantes como é o caso das regras informais.

Assim, e de acordo com a visão sustentada por autores na esteira de O’Donnell, o simples fato de haver institucionalização de regras democráticas não quer dizer que a democracia esteja consolidada, pois se torna importante analisar também outras dimensões sociais, designadamente as informais, que interferem ou influem no processo democrático enquanto um complexo sistema de regras e valores sociais. Neste sentido, não se pode afirmar que a democracia cabo-verdiana já esteja consolidada, apesar dela não registrar nenhuma onda reversa desde a sua instauração em 1991.

De fato, Cabo Verde goza de grande prestigio internacional quanto à performance da sua democracia e dos aspectos procedimentais conducentes a chegada do poder, chegando mesmo a ser considerado por instituições internacionais, como as Nações Unidas, como 
exemplo de democracia em África. Todavia, se considerarmos a visão de O`Donnell (1996) avançada acima, da qual este artigo partilha, chegaremos à conclusão de que estaríamos a ser demasiados reducionistas quanto às possibilidades de consolidação democrática em Cabo Verde na medida em que ficariam fora da equação importantes aspectos informais cuja presença se manifesta numa relação conflituosa com as regras formais ou institucionais da democracia.

Tais aspectos vêm sendo, recentemente, assumidos pelo discurso oficial quando o ainda Primeiro-Ministro, José Maria Neves, reconheceu publicamente a existência e crescimento de um suposto "jeitinho cabo-verdiano", fazendo analogia ao conhecido "jeitinho brasileiro".

Esse fenômeno, prática tradicional da política e característica histórica presente na formação e trajetória social cabo-verdiana, contribui do ponto de vista substantivo para a fragmentação democrática, pois impede que os benefícios sociais, econômicos e políticos da democracia sejam distribuídos de forma equitativa a todas as camadas sociais.

\section{REVISITANDO O CONCEITO DE CULTURA POLÍTICA}

O trabalho empírico sobre a cultura cívica em cinco democracias, publicado por Almond e Verba em 1963, inaugurou um novo campo de estudos na Ciência Política designado de Cultural Studies. A emergência dos Cultural Studies na arena política e acadêmica internacional veio associada a um renovado interesse da Ciência Política nas variáveis psicológicas e culturais dos indivíduos como explicação da variação da estabilidade democrática nos diferentes sistemas políticos contemporâneos.

A ideia de que certas características da sociedade (como virtudes cívicas, valores, crenças e atitudes políticas e comportamentos individuais) são fundamentais para a estabilidade dos sistemas políticos não se mostra como nova ou recente, pois tantoPlatão quanto Aristóteles já haviam discorrido sobre elas durante o período clássico antigo.

Todavia, a preocupação com os valores cívicos das sociedades e sua importância na solidificação dos sistemas políticos ressurge a partir da segunda metade do século XX, período pós-II Guerra Mundial com a publicação de "The Civic Culture”. Neste âmbito, o desenvolvimento político das (novas) nações tem se constituído em objeto de estudo central por 
parte de autores que procuram buscar as causas explicativas de maior sucesso ou êxito de uma nação relativamente a outra.

Assim, a cultura política, enquanto elemento constitutivo de cultura cívica de uma nação, surge nesses estudos dos quais "The Civic Culture" de Almond e Verba terá sido o primeiro, como variável explicativa da variação da estabilidade e eficácia políticas nas democracias contemporâneas. Neste sentido, os autores da geração do "The Civic Culture" definiram cultura política como sendo "orientações especificamente políticas, posturas relativas ao sistema político e seus diferentes elementos, assim como atitudes com relação ao papel de si mesmo dentro do dito sistema" (ALMOND; VERBA, 1970, p. 30).

Segundo eles, essa concepção de cultura política é elaborada não com a pretensão de tornar-se uma teoria, mas como uma gama de variáveis que podem ser usadas na construção de teorias. Assim, com o termo cultura política de uma sociedade, eles querem referir-se a um conjunto de conhecimentos, sentimentos/afetos e valorações da população em relação ao seu sistema político.

Neste sentido, os autores afirmam ainda que ela consiste numa "particular distribuição de orientações em relação aos objetos políticos entre os membros de uma determinada nação" (p. 31). No modelo formulado por eles, tais orientações, entendidas enquanto aspetos internalizados por indivíduos sobre objetos políticos e suas relações, compõem-se de três dimensões fundamentais, quais sejam: orientação cognitiva, afetiva e avaliativa.

A orientação cognitiva se refere a conhecimentos e crenças acerca do sistema político, de seus papeis e dos incumbentes de tais papeis de seus aspetos políticos e administrativos. Já a orientação afetiva tem a ver com os sentimentos dos indivíduos sobre o sistema político, seus papeis e atores. Por último, a orientação avaliativa se refere aos juízos e opiniões sobre objetos políticos que envolvem a combinação de critérios de valor com a informação e os sentimentos.

Neste âmbito, para os autores, as orientações internalizadas ao longo do tempo pelos indivíduos surgem como mecanismos fundamentais na estruturação da cultura política de uma sociedade, pois interferem naquilo que são as disposições, atitudes e padrões de comportamento dos indivíduos que os levam a participar ou não, ou ainda a ter um determinado tipo de comportamento perante o sistema político em geral e seus diferentes elementos. 


\section{A CULTURA POLÍTICA CABO-VERDIANA}

A análise da cultura política de um povo ou de uma nação implica, a consideração de determinados fatores histórico-estruturais e culturais de um dado sistema político que, numa perspectiva longitudinal, produziram efeitos de longo prazo na configuração dos traços socioculturais e identitários que forjam o imaginário coletivo de um povo.

Como salientam os autores que se inserem na linha culturalista (ALMOND; VERBA, 1970; BAQUERO, 2001; MOISÉS, 2008), a cultura política nacional de um povo não é mais do que a distribuição de padrões de orientações referentes aos objetos especificamente políticos e que são internalizados pelos cidadãos mediante um contínuo processo de socialização política.

Assim, a socialização política enquanto processo contínuo, cumulativo e interativo de experiências vividas e travadas entre os cidadãos e o seu sistema político se revela como importante na determinação da cultura política de um povo, pois possibilita o desenvolvimento de orientações e disposições psicossociais que os leva a ter uma atitude de apoio ou não ao sistema político.

Neste sentido, a cultura política cabo-verdiana precisa de ser examinada no contexto de grandes eventos histórico-estruturais cuja existência e operacionalização tiveram influências diretas ou indiretas no imaginário sociopolítico coletivo do povo das Ilhas.

Esses eventos, dos quais se incluem a colonização, a conquista da independência mediante um processo revolucionário e o advento da democracia, se afiguram como fatores marcantes e estruturantes e que importam analisar desde uma perspectiva de influência na configuração da cultura política cabo-verdiana.

\subsection{FACTORES HISTÓRICO-ESTRUTURAIS DA CULTURA POLÍTICA CABO-VERDIANA}

\subsection{A dominação colonial}


Uma perspectiva teórica que tem dominado o pensamento social sobre a formação da sociedade e cultura crioulas pode ser encontrada em Baltasar Lopes (1947) quando, numa alusão à formação e afirmação da língua crioula em contraposição à afirmação do português no Brasil, afirma que a magra superestrutura social e agrária existente em Cabo Verde teria votado a população ao abandono, fazendo com que esta criasse, aos poucos, uma cultura própria marcada pelo modo crioulo de linguagem (LOPES, 1947, pp. 19-20).

Esse abandono esteve na origem de uma cultura de alienação e distanciamento políticos de grande parte da população cabo-verdiana que durante séculos viu-se impedida de participar e se envolver ativamente em processos de direção política, visto que o poder era imposto mediante lógicas totalitárias e estranhas à própria sociedade (CARDOSO, 1995).

Por outro lado, o sistema de dominação colonial terá sido responsável pela configuração de uma tendência generalizada de valorização das relações familiares, quasi-familiares, patriarcais e de cunho privado. A obra de Cláudio Furtado (1993), intitulada “Transformação das Estruturas Agrárias numa Sociedade em mudança - Santiago, Cabo Verde", retrata o desenvolvimento dessas relações que, no vocabulário político moderno, são conhecidas por relações de clientelismo, clanismo e patronagem (FAORO, 2002)Um extrato dessa obra espelha bem essa relação ao destacar a seguinte afirmação de um trabalhador com relação ao proprietário de terra:

O morgado ele me trata bem e a família. Tenho um filho que é afilhado dele; dá comida, roupa. Nunca tive problemas com ele. Muito pelo contrário, ele trata os parceiros muito bem. Ele é dono das terras e faz o que ele quer. Dá para trabalhar as terras dele para quem ele quiser (...) (FURTADO, 1993, p. 118).

Assim, essa relação pautada por um vínculo de dependência, familiaridade e de patronagem, associada ao afastamento do poder e da sua natureza estrangeira e totalitária na acepção de Cardoso (1995), terá impedido o surgimento de uma cidadania independente, autônoma (COSTA, 2013) e consciente dos seus direitos e deveres cívicos e políticos perante o sistema político.

Deste modo, na ausência do desenvolvimento de um padrão de comportamento orientado para a ação política, ou seja, voltado para as estruturas de input, terá desenvolvido no seio da população um padrão de orientação de comportamento que se insere, segundo a categoria proposta e desenvolvida por Almond e Verba (1970), numa corrente inferior de 
imposição política da qual o processo administrativo, que incorpora as estruturas de output, se afigura como expressão mais perfeita e acabada.

Neste sentido, desenvolveu-se uma cultura política que Almond e Verba (1970) chamariam "de imposição" ou “de súdito" em contraposição à cultura política "de participação" desenvolvida em sociedades mais avançadas, como são os casos, por exemplo, da Inglaterra ou dos Estados Unidos da América (ALMOND; VERBA, 1970, pp. 32-33).

De fato, durante o período colonial, não parece ter havido mecanismo de accountability $^{4}$ social horizontal (DIAMOND; MORLINO, 2004) ou de interação bottom- up ${ }^{5}$ (TILLY, 1997) que pudessem contribuir para a germinação e fortalecimento de uma orientação que enaltecesse e valorizasse a participação em espaço público como um fator essencial ao desenvolvimento sociopolítico e econômico da nação.

Todavia, existe no pensamento social cabo-verdiano uma perspectiva teórica sustentada por Baltazar Lopes da Silva (1974) segundo a qual o abandono a que os cidadãos foram sujeitados, bem como as precárias condições socioeconômicas, terá desenvolvido uma "democracia social" na qual:

As classes sociais não são categorias fechadas e estanques. O mesmo indivíduo pode conhecer durante a sua vida diversos escalões de consideração social, independentemente das circunstâncias do seu nascimento ou da cor da sua pele, tudo consoante o seu comportamento perante as perspectivas de acesso social (LOPES, 1947, p. 9).

Essa perspectiva teórica tem sido frequentemente usada na literatura cabo-verdiana como possível explicação da relativa estabilidade democrática em Cabo Verde, comparativamente com as suas congêneres africanas, nas quais predominam focos permanentes de instabilidade política e democrática decorrentes de uma cultura política não democrática e fortemente fragmentada (SILVEIRA, 2005; PINA, 2006).

\footnotetext{
${ }^{4}$ Referindo-se à questão de prestação de contas, este termo tem sido, nos últimos anos, muito utilizado na literatura das ciências sociais contemporâneas na análise da qualidade democrática. Autores como Diamond e Morlino (2004) consideram-no como uma das principais dimensões na análise da qualidade democrática. Para mais informação, ver: DIAMOND; MORLINO, 2004.

${ }^{5}$ Termo muito usado na literatura dos movimentos sociais para se referir a estratégias de mobilização de baixo para cima, ou seja, estratégias originadas no seio da sociedade civil.
} 
Todavia, se atendermos às condições indispensáveis ao nascimento da democracia como "autogoverno", que pressupõe existência de organizações sociais autônomas e garantia de direitos civis e políticos básicos como a liberdade, a igualdade e a participação sociopolítica, verificaremos então que, no caso cabo-verdiano, todas essas condições não só não estavam garantidas ou salvaguardadas, como impedidas à nascença.

\subsubsection{O SISTEMA DE PARTIDO ÚNICO E A EMERGÊNCIA DO "LEVIATÃ CRIOULO"}

O independência de Cabo Verde em 1975 não veio acompanhada da instauração de um sistema político que pudesse ser considerado democrático nos termos da definição proposta por Dahl (2005) em seu clássico trabalho sobre a "Poliarquia” e da qual os críticos consideraram como sendo a definição mais completa ou apropriada para o termo "democracia” (O'DONNEL, 1996, p. 34).

Nesse trabalho, Dahl (2005) define democracia como um sistema que tenha por base a participação e a contestação dos cidadãos ao governo. Em suas próprias palavras, a democracia seria "um sistema político que tenha, como uma de suas características, a qualidade de ser inteiramente, ou quase inteiramente, responsivo a todos os seus cidadãos" (DAHL, 2005, pp. 25-26).

$\mathrm{Na}$ verdade, o sistema político erigido logo após a Independência Nacional, embora tivesse sido classificado nos vários documentos oficiais, designadamente nos do Partido e na Constituição de 1980, como “democracia nacional revolucionária”, não se enquadrava dentro da definição desenvolvida por Dahl (2005) do que seria considerada uma democracia, ou melhor, uma poliarquia.

\footnotetext{
${ }^{6}$ A expressão "crioulo" é uma categoria usada para caracterizar o povo cabo-verdiano e a sua cultura. Este termo surgiu da simbiose das culturas europeia e africana durante o período do povoamento e colonização do Arquipélago. Contudo, é preciso salientar a não exclusividade deste termo ao caso cabo-verdiano, pois se aplica também a outras culturas resultantes do processo de colonização, como são os casos de alguns países da Africa (ex.: Guiné-Bissau) e do Continente americano (Haiti). Outrossim, o Termo "Leviatã Crioulo" cunhado pelo historiador cabo-verdiano, António Leão Correia e Silva (2001), resulta de uma analogia ao Leviatã hobbesiano que propõe um Estado Omnipresente e Todo Poderoso por forma a solucionar um tal estado de natureza marcado pela "Guerra de todos contra todos".
} 
Não se enquadraria porque uma dimensão importante da poliarquia, qual seja, a contestação, estaria sendo colocada de lado e, além disso, todos os sete critérios procedimentalistas $^{7}$ avançados por ele como definidores da poliarquia não estariam salvaguardados pelo regime.

Assim, embora num contexto de maior legitimidade institucional comparativamente ao sistema colonial, a relação entre o Estado e a sociedade seguiu sendo pautada, durante esse período, por lógicas autoritárias, pois todos aqueles critérios que permitem diferenciar democracia de autoritarismo não se faziam presentes.

Num tal cenário, os valores culturais internalizados e partilhados pelos cidadãos em diversos espaços de convivências e relações interpessoais e institucionais não deixariam de ter, como sugerido por Furtado (2001), em sua essência, um viés marcadamente autoritário.

Neste sentido, a cultura política continuou sendo marcada pela imposição por parte das estruturas burocráticas ou administrativas do Estado, impedindo assim o desenvolvimento de uma orientação participante no seio da sociedade civil capaz de se constituir em um instrumento de influência e controle social nas decisões políticas.

Esse fato sedimentou ainda mais a internalização de orientações cognitivas, afetivas e valorativas inibidoras, quer da participação ativa dos cidadãos nas estruturas de input, ou seja, na canalização de demandas a partir da sociedade civil e no controle e fiscalização dos incumbentes do poder, quer no reconhecimento do seu próprio papel enquanto sujeito ativo e útil na arena política.

Portanto, o período que se sucedeu à colonização e se estendeu até à liberalização do regime ocorrida em fevereiro de 1990 fica marcado pela presença de uma cultura política que se caracteriza pelo autoritarismo, pois cabia ao Estado, nesse caso, o Partido Único que se auto intitulava de "força dirigente da sociedade e do Estado" (CRCV, art. 4. ${ }^{\circ}$ ), a organização das

\footnotetext{
${ }^{7}$ Em A Poliarquia (2005), Dahl assinalava para oito critérios definidores de um regime democrático e numa publicação posterior (2001) ele os resumiu em seis, quais sejam: 1) Funcionários eleitos; 2) Eleições livres justas e frequentes; 3) Liberdade de expressão; 4) Fontes de informação diversificada; 5) Autonomia para as associações e, 6) Cidadania inclusiva.
} 
massas populares em estruturas partidárias que depois eram objeto de instrumentalização ou manipulação política.

Neste sentido, instituía-se uma cultura política de passividade ou de sujeição (ALMOND; VERBA, 1970) em relação às estruturas político-partidárias do sistema, obstaculizando assim a emergência de grupos sociais ou organizações autônomas da sociedade civil que pudessem incentivar o autogoverno enquanto requisito essencial para o bom funcionamento de um regime democrático.

Por outro lado, esse sistema terá sido responsável pela germinação de uma cultura cívica inativa que leva à concepção de um ser social não como agente ativo capaz de contribuir para a transformação da sua realidade, mas sim de um ser que procura sempre "uma razão externa à sua existência" (BAQUERO, 2001, p. 100).

A busca de causas externas como condição de sobrevivência e existência do caboverdiano é algo que não só lhe é intrínseco e constitutivo do seu imaginário sociopolítico, como também se afigura como elemento que perpassa ou permeia a totalidade do horizonte da sua relação e interação societárias.

Essa constatação pode ser encontrada em diversos trabalhos dos literatos e intelectuais cabo-verdianos que, quer através da poesia, prosa e música, quer através de ensaios e textos vários, expressaram a cultura e a mundivivência das relações do cabo-verdiano com o próprio, com o seu país e com o mundo.

Uma perspectiva teórica dominante desses estudos é aquela surgida no âmbito da "Revista Claridade" da qual o evasionismo implícito no poema intitulado "Écran" de Manuel Lopes (1936), aparece como uma das características marcantes do cabo-verdiano dadas as condições limitativas impostas pelo sistema colonial.

Assim, fatores desse tipo associados a uma opção institucional que enfatiza e reforça a solução hobbesiana do Estado centrada nas restrições aos direitos civis e políticos naturais ou

\footnotetext{
${ }^{8}$ Revista literária e cultural Cabo-verdiana fundada em 1936 e que, por meio de poesias, prosas, ficção, textos e artigos de âmbito literários visava, por um lado a contestação e a chama de atenção das autoridades coloniais para as duras condições de existência experimentadas pelo povo do arquipélago e, por outro, o amor à pátria-mãe bem como a exaltação da sua cultura como um caso peculiar, ou seja, próprio do povo crioulo.
} 
básicos em contraposição à solução putnamiana que enaltece o potencial das virtudes cívicas no relacionamento entre os cidadãos e entre estes e o Estado, obstaculizaram o desenvolvimento de orientações cognitivas que pudessem conduzir a uma maior participação sociopolítica.

Além disso, esse fato terá contribuído para o desenvolvimento de um sentimento generalizado de impotência política na maioria dos indivíduos, levando-os a autocensurar-se perante os objetos políticos e a internalizar a ideia de que não compreendem e nem têm suficiente capacidade para influir na política quer em nível nacional, quer em nível subnacional regional ou local.

A concepção ou a imagem do indivíduo que terá prevalecido nessa sociedade parece ser aquela que enaltece e privilegia a passividade, visto que, para a maioria desses indivíduos, talvez significasse a mesma coisa a sua participação ou não, na medida em que o sentimento amplamente partilhado é aquele que reforça a sua impotência e incapacidade de contribuir de forma significativa para a alteração do status quo.

Basta notar, por exemplo, a tendência generalizada no seio desta sociedade em tentar fugir ou evitar discutir assuntos públicos ou políticos na esfera pública, bem como a tendência de atribuir maior supremacia à esfera privada das interações pessoais [desenvolvida no núcleo familiar e grupo de amigos] do que à esfera pública de partilha e interação abrangente com diferentes grupos sociais independentemente dos laços familiares ou quase familiares que eventualmente os une.

\subsubsection{TRANSIÇÃO DEMOCRÁTICA E RECONVERÇÃO DO SISTEMA POLÍTICO}

A teoria transitológica, cuja emergência pode ser enquadrada no campo da ciência política, tem conhecido enorme desenvolvimento a partir da década de 1980, sobretudo com os acontecimentos verificados ao nível das transições de regime (autoritário/democrático) em países do sul e leste europeus bem como da América Latina e África, configurando assim aquilo que Samuel Huntington viria a designar de terceira onda da democratização (HUNTINGTOM, 1994). 
Autores marcantes dessa teoria, como O’Donnell e Schmitter (1986, p. 6), concebem a transição como sendo um processo delimitado, por um lado, por um processo de dissolução de um regime autoritário e, por outro, pela implantação de um regime democrático; pela reversão ou transformação da democracia em alguma forma de autoritarismo, ou ainda pela emergência de uma opção revolucionária.

Em Cabo Verde, o processo que culminou com a transição democrática do regime concretizada em 1991 - a quando da realização das primeiras eleições livres, pluripartidárias e de voto secreto - se iniciou a partir dos finais da década de 1980, por ocasião do III Congresso do PAICV $^{9}$ (1988) quando, pela primeira vez, se colocou sobre a mesa o problema da Abertura Política e Econômica do Regime de Partido Único (LOPES, 2012, p. 343).

Contudo, como explica Aristides Pereira, ex-secretário-geral do PAICV e ex-presidente da República, a questão da abertura política não se efetivou durante o III Congresso devido à forte resistência da ala conservadora, que se posicionou contra a eventual liberalização política do regime, levando o próprio Aristides Pereira a assumir, depois de deixar o Poder, que "o resultado do Congresso foi uma frustração (...) ou que ficou aquém do esperado (...)” ( pp. 343$345)$.

Devido à falência e ao esgotamento do modelo de Partido Único, a abertura política se mostrava inevitável e viria a ser anunciada pelo Conselho Nacional do PAICV a 19 de fevereiro de 1990 ( p. 347). Todavia, esse processo de abertura de dissolução do regime autoritário e, a consequente implantação do regime democrático, não implica na mudança automática naquilo que são as orientações e padrões de comportamento dos indivíduos internalizados ao longo do tempo.

Leonardo Avritzer (1995), analisando os casos de transição democrática no Leste Europeu e na América Latina, em particular no Brasil, considera a existência de uma cultura política que se mantêm ao longo do autoritarismo, sugerindo assim o entendimento da

\footnotetext{
${ }^{9}$ Partido Africano da Independência de Cabo Verde. A sigla inicial deste Partido era PAIGC (Partido Africano da Independência da Guiné e Cabo Verde) fundado em 1956 na sequência da emergência dos movimentos nacionalistas de luta de libertação. Todavia em 1981, após o primeiro Golpe de Estado ocorrido na Guiné-Bissau a 14 de Novembro de 1980, os dirigentes partidários cabo-verdianos mudaram a sigla para a atual como uma das medidas tomadas após a crise política naquele país irmão.
} 
democratização como um processo mais longo de transformação da cultura política e das relações entre o Estado e a sociedade.

Por outro lado, ele critica a teoria transitológica que parece dar como garantida a mudança nos padrões de comportamento e adesão linear aos valores democráticos motivados pela instauração da democracia.

Para ele, a mera transição democrática não é suficiente para a transformação da cultura política na medida em que o processo de transição não necessariamente encerra ou esbarra, automaticamente, em uma cultura política democrática.

Analisando o caso cabo-verdiano, verifica-se uma ampla adesão, tanto da elite política quanto da massa, aos valores e princípios democráticos dando a perceber que nesse país terá havido uma transformação imediata nos padrões de comportamento da população.

Evidências empíricas como: inexistência de tumultos, violências e desordens durante e depois do processo de transição democrática (Meyns, 2002); prevalência de lógicas do "Poder Civill" e a submissão do "Poder Militar" àquele em contraposição ao país irmão [Guiné-Bissau] (Koudawo, 2001), bem como dados de pesquisa de opinião advenientes do primeiro survey realizado em 2002 sobre "atitudes políticas e democracia" sinalizaram para a construção de uma narrativa que apregoa o êxito e o sucesso democrático em Cabo Verde.

Contudo, uma análise mais profunda dos dados, associada a uma concepção de consolidação democrática mais abrangente conforme é advogada aqui, mostra níveis significativos de incongruências entre atitudes de cidadãos e regime democrático, bem como uma compreensão difusa daquilo que realmente a democracia significa, além de crescentes níveis de desconfianças interpessoal e institucional.

\section{ESTUDOS EMPÍRICOS:}

4.1 ANÁLISE DE RESULTADOS DE DADOS SOBRE A QUALIDADE DA DEMOCRACIA E DA GOVERNAÇÃO EM CABO VERDE (2002 - 2014) 
Em Cabo Verde, o primeiro estudo empírico sobre as atitudes dos cidadãos em relação à democracia foi publicado ao final de 11 anos da instalação do regime democrático, em 2002, pelo que a análise dos dados recobre o período compreendido entre 2002 a 2014.

A tabela 1 nos coloca perante uma situação paradoxal entre apoio à democracia e satisfação com o seu funcionamento. Se em termos de apoio à democracia uma grande maioria da população manifesta níveis elevados cuja média se situa na casa dos 76 pontos percentuais, em termos do seu funcionamento a manifestação de satisfação tem se situado em níveis muito abaixo dos 50 pontos percentuais o que indicia que grande maioria da população não está satisfeita com a maneira como tem funcionado a democracia.

É de realçar ainda o fato da manifestação de satisfação se situar sempre em níveis negativos chegando mesmo a registrar uma queda acentuada em 2014 quando apenas $26 \%$ da população se mostraram satisfeitos com a maneira como a democracia tem funcionado. Esses dados confirmam nossa tese, pois evidenciam que o apoio abstrato e/ou difuso à democracia entra em choque com uma avaliação mais concreta e/ou específica da democracia que valorize e enalteça uma dimensão mais substantiva dos benefícios da democracia.

Tabela 1: Percentual de apoio e grau de democracia em Cabo Verde (2002-2014)

\begin{tabular}{l|l|l|l|l|l|l}
\hline \multicolumn{1}{c|}{ Ano } & 2002 & 2005 & 2008 & 2011 & 2014 & Média \\
Questões & 66 & 70 & 81 & 81 & 81 & 75,8 \\
\hline $\begin{array}{l}\text { Apoio à } \\
\text { democracia* }\end{array}$ & 60 & 46 & 47 & 45 & 26 & 39,4 \\
\hline $\begin{array}{l}\text { Satisfação com a } \\
\text { democracia** }\end{array}$ & 33 & & & & \\
\hline
\end{tabular}

Fonte: Relatório Afrobarômetro, 2014.

*Resposta "A democracia é preferível a qualquer outra forma de governo (concorda/concorda fortemente)".

**Resposta "Bastante/muito satisfeito".

Ademais, os resultados desta pesquisa demonstram um crescente descontentamento com o funcionamento da democracia, o que sinaliza para prevalência de demandas sociais e materiais que a democracia ainda não conseguiu superar. Essas demandas em vez de diminuir 
tendem a se cristalizar ou a aumentar ainda mais à medida que a nossa democracia se torna mais longeva.

Uma perspectiva teórica importante no estudo da qualidade e consolidação da democracia tem a ver, precisamente, com a dimensão dos benefícios sociais gerados pela democracia conforme sublinhado por Shin (2005). De acordo com esta perspectiva, uma democracia consolidada é aquela que consegue gerar benefícios sociais para a maioria da população e não apenas para uma pequena classe dirigente que detém o poder.

Por outro lado, esses dados sugerem uma cultura política democrática fragmentada e ambivalente (MOISÉS, 2008) na medida em que simultaneamente os cabo-verdianos tendem, genericamente, a avaliar positivamente a democracia, mas não estão satisfeitos com o seu funcionamento no dia a dia.

Outro indicador importante da cultura política e que incide sobre a consolidação democrática tem a ver com a confiança institucional. Os níveis de confiança institucional em relação às principais instituições democráticas tendem a aproximar-se aos níveis de satisfação com a democracia, conforme pode ser visto na tabela 2 .

Tabela 2: Nível de Confiança Institucional em \% (2002 - 2014)

\begin{tabular}{l|l|l|l|l}
\hline $\begin{array}{l}\text { Até que ponto você confia razoavelmentelmuito em cada uma das } \\
\text { seguintes instituições }\end{array}$ & 2005 & 2008 & 2011 & 2014 \\
\hline O Presidente da República & 47 & 45 & 66 & 57 \\
\hline O Primeiro Ministro & 48 & 45 & 60 & 47 \\
\hline A Assembléia Nacional & 48 & 45 & 58 & 45 \\
\hline O Executivo Camarário (Presidente e Vereadores) & - & 45 & 56 & 41 \\
\hline A Comissão Nacional de Eleições & 44 & 44 & 55 & 45 \\
\hline O Partido no Poder & 44 & 40 & 55 & 39 \\
\hline Funcionário das Finanças & - & - & 52 & 37 \\
\hline Os Partidos Políticos da Oposição & 47 & 38 & 51 & 42 \\
\hline
\end{tabular}

Fonte: Relatório Afrobarômetro, 2015. 
Os dados evidenciam uma tendência geral de queda da confiança institucional em 2014. Ela é ainda mais acentuada em relação às principais instituições democráticas, como a Assembleia Nacional, o Governo, o Partido no Poder e o executivo camarário.

Essa tendência generalizada de queda de confiança institucional demonstra a falta de apoio específico às instituições democráticas gerada em grande parte pelas promessas não cumpridas e pela prevalência de interesses particularistas em detrimento do interesse e bem comuns.

Por outro lado, sucessivos estudos empíricos, como os do Afrobarômetro, têm nos demonstrado que a existência cada vez maior de fatores como o clientelismo, o individualismo e o paternalismo político estão na origem da crescente fragilização social, econômica e política da sociedade gerando assim atitudes de desprezo e/ou desconfiança para com as principais instituições democráticas.

Dados de 2005 apontam que $41 \%$ dos cabo-verdianos entendem que os políticos deveriam ajudar menos a sua família e ao seu grupo, enquanto que $46 \%$ são de opinião que deviam apostar mais em políticas que favorecessem as comunidades em detrimento dos seus grupos mais próximos.

Esses dados sinalizam para uma concepção da política no âmbito da qual as ligações familiares e quasi-familiares ganham maior protagonismo e relevância no relacionamento entre a política e sociedade, obstruindo assim as possibilidades de uma concepção mais abrangente da política e situada fora do núcleo de dominação tradicional da política.

Numa democracia consolidada, o princípio do universalismo político deve se sobreporao do particularismo, pois as regras seguem princípios como os da legalidade, da impessoalidade e racionalidade presentes em uma burocracia moderna.

Conforme pode ser visto na tabela 3, a relação de clientela entre Estado e cidadãos assume níveis elevados, assim colocando em perigo as perspectivas de consolidação, pois além de impedir uma melhor repartição dos benefícios sociais à população, leva ao estabelecimento de atitudes paternalistas e de dependência na relação dos cidadãos com o Estado. 
Tabela 3: Relação de clientelismo entre Estado e cidadãos (em \%)

\begin{tabular}{l|l|l|l}
\hline \multicolumn{1}{c|}{ Ano } & 2002 & 2005 & Média \\
\hline Expressões & & & \\
\hline Responsabilidade individual* & 55 & 48 & 51,5 \\
\hline Intervenção do Estado** & 40 & 42 & 41 \\
\hline
\end{tabular}

Fonte: Relatório Afrobarômetro, 2005.

*Resposta "As pessoas devem olhar por si próprias e assumirem responsabilidades pelo seu próprio sucesso na vida".

**Resposta "O governo deveria assumir a maior parte da responsabilidade pelo bem estar das pessoas".

Ao se analisar os resultados para essas questões, verifica-se a existência de uma sociedade extremamente fragmentada quanto à assunção de responsabilidade para o sucesso na vida. Em termos comparativos, constata-se, de 2002 a 2005, uma redução daqueles que consideram que os cidadãos devem assumir as responsabilidades pelo seu sucesso, o que mostra uma forte atitude de dependência em relação ao Estado. Por outro lado, e embora a média esteja abaixo dos $50 \%$, a proporção daqueles que acham que o governo deveria assumir maior parte da responsabilidade no bem estar das pessoas é muito elevada. Esta situação evidencia uma relação paternalista e clientelista muito forte entre Estado e sociedade, pois grande parte da população transfere as responsabilidades do âmbito individual para o do Estado sinalizando que a esfera estatal se sobrepõe à individual. Aliás, esta é uma característica importante do processo de formação sociopolítica cabo-verdiana, dadas as vulnerabilidades e carências historicamente vivenciadas pelo povo deste arquipélago. Assim, essa teia de relações clientelistas se justifica pela ausência de uma sociedade civil autônoma capaz de desenvolver um padrão de comportamento que enalteça e enfatize relações proativas e não de mera dependência.

\section{CONCLUSÃO}

A democracia política em Cabo Verde se afigura como um fato irreversível. Os dados demonstram que os cidadãos não estão dispostos a dispensá-la enquanto forma de organização social e de interação societária. Todavia, ela ainda não se encontra consolidada na sociedade ao ponto de todos os cidadãos a encararem como um modo ou uma forma natural de vida. Com 
ela, coabita uma parte significativa de atitudes e comportamentos não democráticos que longe de pô-la em causa, impedem a sua consolidação, isto é, o seu fortalecimento.

Por outro lado, se constata uma compreensão difusa dos cidadãos face à democracia que tende a atribuir maior supremacia à democracia enquanto regime político em detrimento de um apoio mais específico de valorização das instituições políticas concretas. A isso, se acresce também o fato de prevalecer ainda atitudes e comportamentos ambivalentes de parte significativa da população que, embora aceite a democracia como o melhor regime político, não dispensaria algumas formas não democráticas de exercício de poder político e da sua relação com a sociedade.

Além disso, assiste-se a emergência de uma tendência generalizada de queda de confiança nas principais instituições democráticas derivada de uma concepção da democracia que ainda se situa longe da dimensão institucional poliárquica mais do que numa concepção que reconheça e enfatize a dimensão substantiva e social da democracia como importantes para a sua consolidação ou fortalecimento. Assim, se conclui que a consolidação democrática é um processo que não deve ser analisado apenas do ponto de vista da perspectiva institucional, mas também do ponto de vista da perspectiva cultural da qual a cultura política e a canalização de demandas sociais por parte dos governos resultam como elementos crucias de sua complementarização.

\section{RESUMO:}

O presente texto discute a relação entre a Cultura Política e Consolidação Democrática em Cabo Verde e procura problematizar as perspectivas de consolidação desde um ponto de vista macrossocial que privilegia as atitudes e os padrões de comportamento dos indivíduos face à democracia. Assim, ancorado em uma proposta metodológica diferenciada, o texto mostra que, embora o grande avanço poliárquico e estabilidade democrática registrados nesses 24 anos de instalação da democracia no país, ela ainda não se encontra consolidada ou totalmente enraizada na sociedade cabo-verdiana, visto que ainda se mantém, em seu bojo, significativas práticas 
políticas tradicionais como os fenômenos de clientelismo e interesses particularistas que impedem a sua materialização enquanto regime que prescreve a soberania popular e o exercício efetivo dos direitos e liberdades civis de todos os cidadãos.

Palavras-chave: Cultura Política. Consolidação Democrática. Transição Democrática. Cabo Verde.

\begin{abstract}
The present text discusses the relation between political culture and democratic consolidation in Cape Verde and seeks to problematize the perspectives of consolidation from a macrosocial point of view that emphasizes the attitudes and patterns of behaviour of individuals in face of democracy. In this manner, supported by a differentiated methodological proposal, the text shows that although the great poliarchic progress and democratic stability registered in this 24 year of democracy installation in this country, she is not yet consolidated or fully rooted in Cape Verdean society . There is still significative traditional political practises (like the phenomenon of clientelism and particularists interests) that prevent her materialization as the regime that prescribes the popular sovereignty and the effective exercise of rights and civil liberties of all citizens.
\end{abstract}

Keywords: Political Culture. Democratic Consolidation. Democratic Transition. Cape Verde.

\title{
REFERÊNCIAS BIBLIOGRÁFICAS
}

ALMOND, Gabriel A. \& VERBA, Sidney. La Cultura Civica. Estudio sobre la Participacion Politica Democratica em Cinco Naciones. Madrid: Fundacion Foessa, 1970.

AVRITZER, Leonardo. Cultura Política, Atores Sociais e Democratização: uma crítica às teorias da transição para a democracia. ANPOCS, 1995. Disponível em: <http://www.anpocs.org.br/portal/publicacoes/rbcs_00_28/rbcs28_09.htm>. Acesso em: 21 fev. 2008.

BAQUERO, Marcello. Cultura Política Participativa e Desconsolidação Democrática. Reflexões sobre o Brasil Contemporâneo. São Paulo em Perspectiva, São Paulo, vol. 4, nº 15 , p. $98-104,2001$.

CABRAL, Águido et al. A Qualidade da Democracia e da Governação em Cabo Verde. Afrobarometer. Cape Town: Idasa, 2011. Disponível em: 
http://afrobarometer.org/sites/default/files/media-briefing/cape verde/cve_r5_presentation1.pdf. Acesso em: 21 de agosto 2015.

CARDOSO, Humberto. Sociedade e Poder em Cabo Verde. Cidade da Praia, 1993. Disponível em: https://sites.google.com/site/humbertocardoso/sociedadeepoderemcaboverde. Acesso em 23/08/15.

DAHL, Robert A. Sobre a Democracia. Brasília DF: Universidade de Brasília, 2001.

DAHL, Robert. Poliarquia: Participação e Oposição. $1^{a}$ Ed. São Paulo: Editora da Universidade de São Paulo, 2005.

DIAMOND, Larry. Toward Democratic Consolidation. Journal of Democracy, John Hopkins University, vol.5, n³, p. 4 -17, 1994.

DIAMOND, Larry; MORLINO, Leonardo. The Quality of Democracy. An Overview. Journal of Democracy, Washington, v. 15, n. 4, p. 20-31, 0ct. 2004

ÉVORA, Roselma. Cabo Verde: A Abertura Política e a Transição para a Democracia. Cidade da Praia: Editora Spleen, 2004.

FAORO, Raymundo. Os Donos do Poder. Formação do Patronato Brasileiro. $3^{\mathrm{a}}$ Ed. revista. São Paulo, 2001.

FURTADO, Cláudio. A Transformação das Estruturas Agrárias numa Sociedade em Mudança. Praia: ICLD, 1993.

HUNTINGTON, Samuel. A Terceira Onda. A Democratização no Final do séc. XX. São Paulo: editora ática, 1994.

KOUDAWO, Fafali. Cabo Verde e Guiné-Bissau: Da Democracia Revolucionária à Democracia Liberal. Bissau: INEP, 2001.

LINZ, Juan J. \& STEPAN, Alfred. Problems of Democratic Transition and Consolidation. Baltimore: Johns Hopkins University Press, 1996.

LOPES, Baltasar. Uma Experiência Romântica nos Trópicos. Revista Claridade, São Vicente, vol. 1 e 2, p. 1-10, setembro de 1947.

LOPES, José Vicente. Aristides Pereira: minha vida, nossa história. Cidade da Praia: Spleen Edições, 2012.

LOPES, Manuel. (1936). Écran. Revista Claridade, São Vicente, nº1, p. 7, 1936.

MAIWARING, Scott. Transition to Democracy and Democratic Consolidation: Theoretical and Comparative Issues. Kellogg Institute, Working Paper 130, p. 1-43, 1989.

MEYNS, Peter. Cape Verde: An African Exception. Journal of Democracy, John Hopkins University Press, vol. 13, n³, p. 153-165, july 2002. 
MOISÉS, José Álvaro. Cultura Política, Instituições e Democracia: lições da experiência brasileira. RBCS, vol.23, nº 66, p. 11-44, 2008.

O’DONNELL, Guilhermo. Illusions about Consolidation. Journal of Democracy, John Hopkins University Press, vol. 7, n², p. 34-51, 1996.

O'DONNELL, Guillermo \& SCHMITTER, Philippe C. Transitions from Authoritarian Rule. Baltimore: John Hopkins University Press, 1986.

PINA, Leão Domingos J. L. (2006). Valores e Democracia em Cabo Verde: Entre Adesão Formal e Embaraço Cultural. Brasília: UNB, 2006, 143 f. Dissertação (Mestrado em Sociologia), Programa de Pós Graduação em Sociologia, Instituto de Ciências Sociais Universidade de Brasília, Brasília, 2006.

PRZEWORSK, Adam. (1984). Ama a Incerteza e serás Democrático. Novos Estudos, São Paulo: Cebrap, nº 9, p. 36-46, jul. 1984.

REIS, Deolinda et al. Atitudes em Relação à Qualidade da Democracia em Cabo Verde. Cape Town: Idasa 2005, working paper n. 53. Disponível em: http://www.afrobarometer.org/publications/atitudes-em-rela\%C3\%A7\%C3\%A3o-\%C3\%A0qualidade-da-democracia-em-cabo-verde. Acesso em: 21/08/15.

SCHEDLER, Andreas. (2001). Measuring Democratic Consolidation. Studies in Comparative International Development, vol. 36, nº 1, pp. 66-92, 2001.

SCHEDLER, Andreas. What is Democratic Consolidation. Journal of Democracy, vol. 9, $\mathrm{n}^{\circ} 2$, p. 91-107, 1998.

SEMEDO, José et al. A Qualidade da Democracia e da Governação em Cabo Verde. Cape Town: Idasa, 2014. Disponível em: http://www.afrobarometer.org/sites/default/files/mediabriefing/cape-verde/cve_r6_presentation1_democracy.pdf. Acesso em: 21/08/15.

SHIN, D. C. Democratization: Perspective from Global Citizenries. In: DALTON, R. e KLINGEMANN, H-D (eds). The Oxford Handbook of Political Behavior. Oxford: Oxford University Press, 2005.

SILVEIRA, Onésimo. A Democracia em Cabo Verde. Lisboa: Edições Colibri, 2005.

TILLY, Charles. (1997) The Top-down and the Bottom Up Construction of Democracy. In ETZIONI-HALEVY, Eva (Ed). Classes and Elites in Democracy and Democratization: A Colection of Reading. New York: Garland Publ., p. 274-284, 1997.

WALZER, Michael. The Civil Society Argument. Gunnar Myrdal Lecture: University of Stockholm, p. 1-11. 1990.

Recebido em: 01/02/2016

Aprovado em: 12/05/2016 